\title{
Preliminary Study of the using KY-038 Sensor Based on Arduino UNO and LabView to Determine the Pulse Rate
}

\author{
Nur Afifah Zen*, ${ }^{1}$ Slamet Indriyanto, ${ }^{1}$ Indah Permatasari, ${ }^{1}$ Juwansyah Sasmita, ${ }^{2}$ and Lia Yuliantini ${ }^{2}$ \\ ${ }^{I}$ Faculty of Telecommunications and Electrical Enginering, Institut Teknologi Telkom Purwokerto, \\ Jl. DI. Panjaitan 128 Purwokerto 53147 \\ ${ }^{2}$ Department of Physics, Institut Teknologi Bandung, Jl. Ganesha 10 Bandung 40132
}

\begin{abstract}
The KY-038 sensor module is designed using Arduino UNO and LabView to allow human pulses. The experiment was carried out by making a design consisting of the KY-038 sensor module, Arduino UNO, and LabView on a computer. LabView software is used to display pulse wave patterns. Measurement of the pulse will involve human objects with variations 3 namely relax (sit), sit, and after running in place. The experimental results show that the different activities affect the voltage released on a chart that has a rating of 3-3.5 V. The more activities that are carried out before retrieving the pulse data, the greater the voltage that is read on the LabView results graph. After running in place, the value of the voltage and pulse are $3.5 \mathrm{~V}$ and 97 beats per minute, respectively.
\end{abstract}

Keywords: Ardunio UNO; KY-038; LabView.

*Corresponding author: afifah@ittelkom-pwt.ac.id

http://dx.doi.org/10.12962/j24604682.v16i2.6092

2460-4682 (CDepartemen Fisika, FSAD-ITS

\section{INTRODUCTION}

Sensor measurements will convert the data received into a signal or visual display so that it can be interpreted by other electronic devices [1]. One of the sensors that will be used in this experiment is the KY-038 sensor. The sensor allows to detect human pulse in real-time. Heart is a vital organ that is very important in human life. A heart rate/pulse chart pattern can provide information on the state of the heart as well as the speed of the heart's impulses. A person's health condition can be known by looking at heart rate patterns [2].

Heart pulse measurements can be observed at various points. One of the best points is on the part of the body that has a radial artery. Blood pressure in this artery can be felt up to $30-38 \mathrm{mmHg}$ and pulse pressure up to $5 \mathrm{mmHg}$ [3]. Several previous studies have reported pulse sensors as a heart beat detector $[4,5]$. This sensor works by firing light into human skin, when the heart drains blood in the arteries, the light intensity that is received by the detector becomes smaller. However, this sensor has the disadvantage that the measurement is easily disturbed by outside light such as sunlight or lamp. Therefore, in this study, the KY-038 sensor is used to detect human heart beat. The sensor works using the sound wave principle so that it can be used well in bright or dark conditions.

KY-038 sensor is used to detect low-frequency signals and then displayed as pulse wave patterns on LabView. KY-038 sensor works based on the size of the sound wave strength on the sensor membrane to produce electrical quantities. One component included in this sensor is the condenser microphone or mic [1]. The KY-038 sensor module circuit has 3 main components, namely the sensor unit, amplifier, and com-
TABLE I: Specifications of Arduino Uno [7].

\begin{tabular}{ll}
\hline \hline Microcontroller & Atmega328 \\
Operating Voltage & $5 \mathrm{~V}$ \\
Input Voltage (Recommended) & $7-12 \mathrm{~V}$ \\
Input Voltage (limits) & $6-20 \mathrm{~V}$ \\
Digital I/O pins & $14(6 \mathrm{PWM})$ \\
Analog Input Pins & 6 \\
DC Current per I/O Pin & $40 \mathrm{~mA}$ \\
DC Current for 3,3V pin & $50 \mathrm{~mA}$ \\
Flash Memory & $32 \mathrm{~KB}$ which 0.5KB \\
& used by bootloader \\
SRAM & $2 \mathrm{~KB}$ \\
EEPROM & $1 \mathrm{~KB}$ \\
Clock Speed & $16 \mathrm{MHz}$ \\
\hline \hline
\end{tabular}

parator. The sensor unit is located on the front of the module in the form of a condenser mic to detect the sound signal and send it to the second unit. The function of amplifier is to strengthen the signal received by the sensor unit and sends the signal to the analog output section of the sensor module. The sensitivity level of the sensor depends on the value of the adjustable potentiometer. The function of comparator is to compare the output of the second unit and a reference signal, then send it to the digital output section. There is an LED indicator if the signal drops below a certain specific value [6]. Arduino UNO has specifications as shown in Table I [7].

LabView (Laboratory Virtual Instrumentation Engineering Workbench) is a software used to design and program an instrumentation system with a visual programming language from National Instruments. LabView is also called Virtual In- 


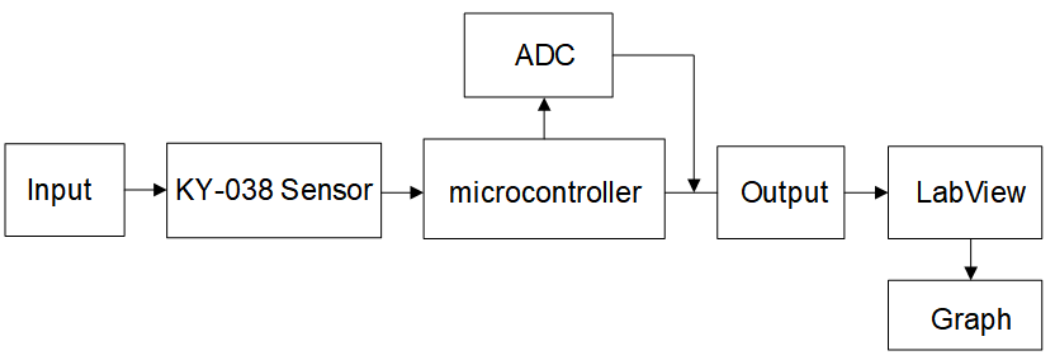

FIG. 1: Block diagram of working principle of sensor KY-038.

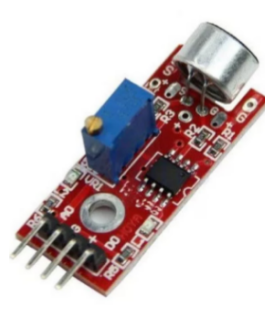

(a) Sensor module

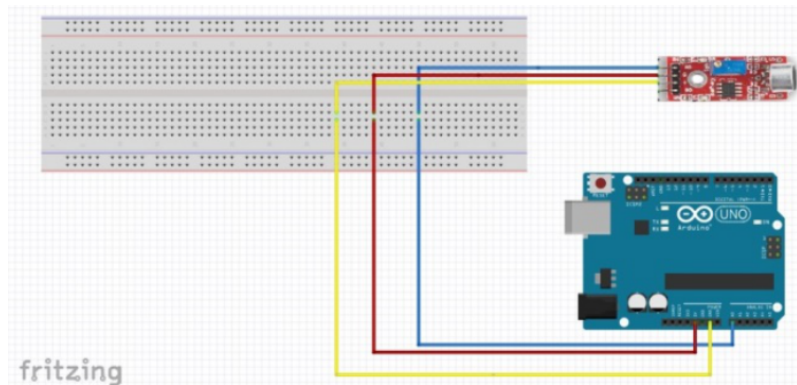

(b) Set-up experiment

FIG. 2: (a) KY-038 sensor module and (b) Set-up experiment module.

struments (VIs). Each Virtual Instrument has 3 components, namely block diagrams, front panels, and connector panels. Block diagrams are panels that are used to arrange programs. The front panel displays the results of programs that have been written on the block diagram, and the connector panel is used to represent virtual instruments in a block diagram [8].

\section{METHODOLOGY}

Arduino UNO, Breadboard, male-female and male-male jumper cables, LabView software are used to developed the system in this research. The block diagram of sensor works can be seen in Fig.1. The schematic experiment module can be seen in Fig. 2 which was created using fritzing software.

The success of the experiment scheme is marked by LEDs on Arduino and the sensor module that will light up. Other indicators can also be installed on the breadboard LED lights as an indicator if the system is functioning properly. The results of the pulse will be displayed in the form of a pulse wave pattern in the LabView software. The experimental method is illustrated by the flow chart in Fig. 3 .

Figure 3 shows the flow of research carried out. Making the system and making the program on Arduino and LabView is done in stages to find out if there is an error in the program. In the testing phase, if the system is running it will continue to the data retrieval stage, but if there are still errors it will be checked on the hardware circuit and the program created.

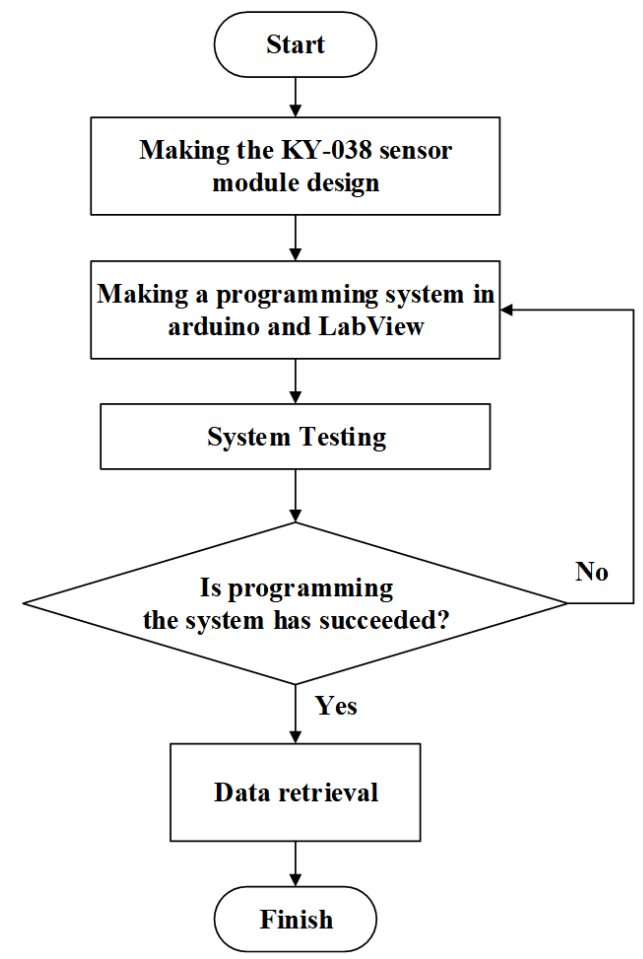

FIG. 3: Research flow chart. 


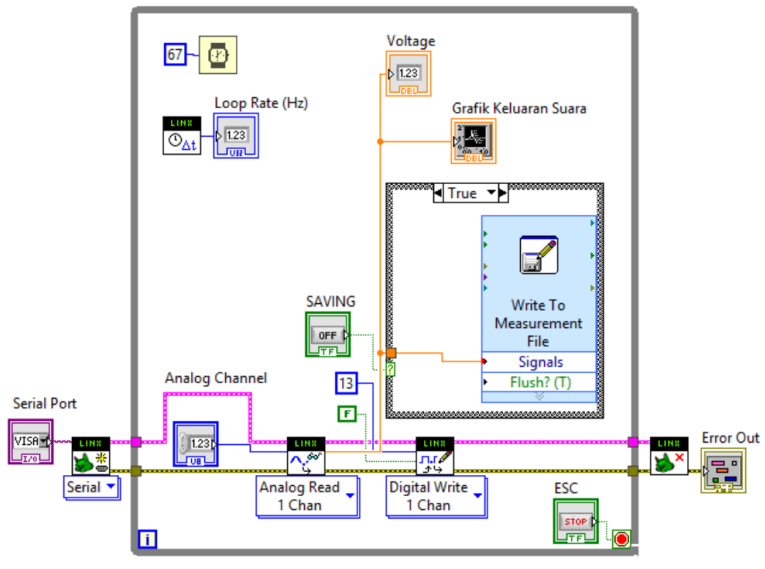

FIG. 4: Block diagram of LabView.

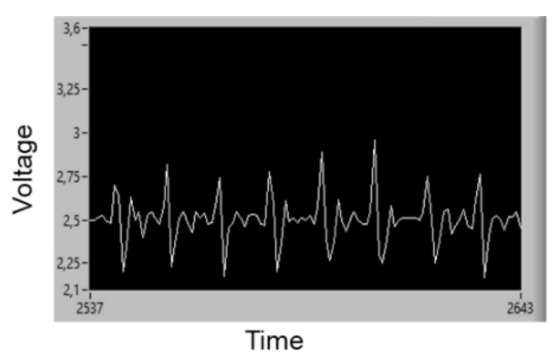

(a) lying down

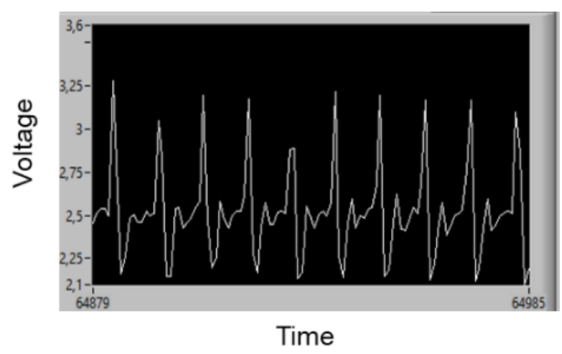

(b) sitting

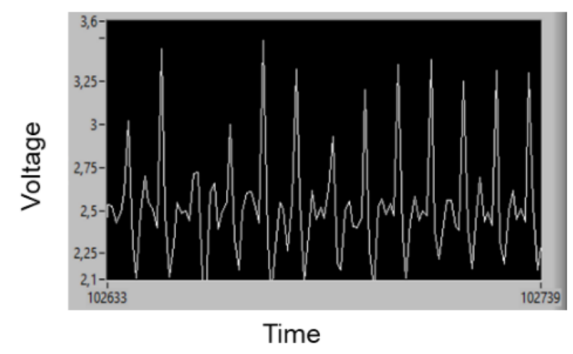

(c) after running in place

FIG. 5: LabView results in detecting a pulse when (a). lying down, (b). sitting, and (c). after running in place.

\section{RESULTS AND DISCUSSION}

The graph of relationship between voltage and time that is presented in LabView software is obtained from the experiment. Fig. 4 shows the block diagram of LabView that can

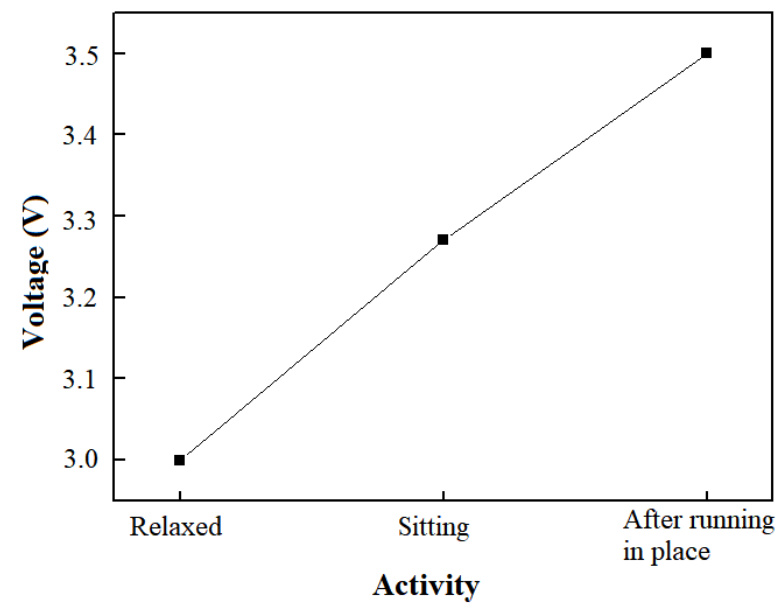

FIG. 6: Maximum voltage when on the activities.

be saved and modified as required in the research. LabView block diagrams can convert analog to digital signals, and vice versa from digital to analog. If the system on LabVIEW has not been successful the indicator is on the graph generated from the pulse waveform at the time of measurement. Data collection was performed on healthy men aged 29 years. Voltage data retrieval in 3 conditions, namely (1) lying down, (2) sitting, and (3) after running in place. Wave patterns resulting from several conditions are shown in Fig.5.

Fig. 5 shows that the more activities carried out by the body, the greater the maximum stress achieved for each state. The pulse pattern obtained from the experimental results follows the reference [9]. The resulting pulse wave pattern shows that the higher the activity carried out, the denser of wave pattern form. The magnitude of the maximum voltage at the same time and resulting from several conditions can be seen in Fig. 6.

The graph in Fig. 6 shows real-time monitoring of the human pulse where the highest voltage is obtained at the time of data collection after running in place. Similar research states that a person's pulse varies depending on conditions during measurement [3]. The value of the voltage obtained is directly proportional to the activity carried out. The highest stress value is found in activities after running in place that is equal to $3.5 \mathrm{~V}$. The frequency of pulses produced from human activities can be seen in Fig. 7 .

The frequency of the human pulse contained in the graph is the average pulse frequency with a range of frequencies in each activity that is $60-97$ beats per minute. The data obtained show that the value of the human pulse according to the reference is that humans have a pulse that ranges between 60-100 beats per minute [10]. From the two graphs in Fig. 6 and Fig. 7, it can be seen the relationship if the voltage slides straight with human activity and the pulse frequency. 


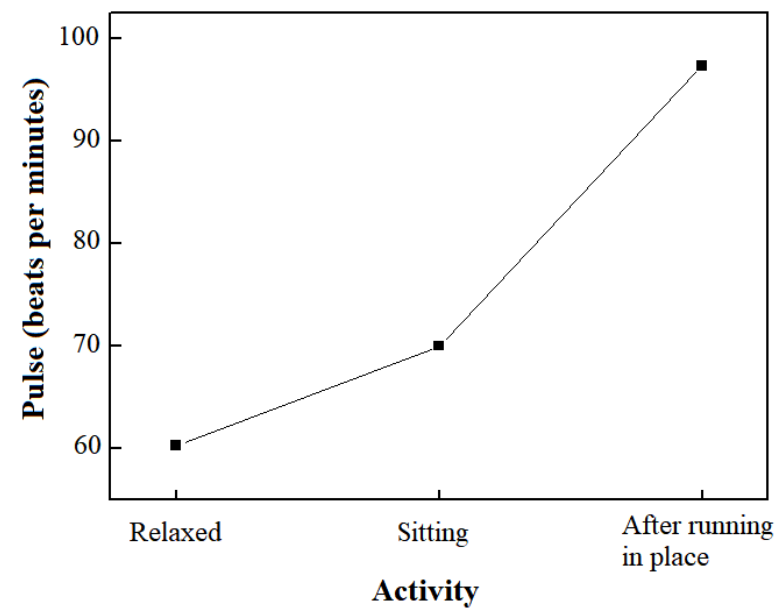

FIG. 7: Pulse rate in several activities. were developed by combining the Arduino microcontroller and LabView to detect a pulse that has a wave pattern. The results of sensor measurements show that the higher the activity, the faster the heart rate and has a higher voltage than the state of inactivity (lying/relaxing). Waves produced in each state have a different pattern, wherein the state after activity (running in place) produces a tighter wave pattern than in a relaxed state which indicates that at the same time producing faster pulses. The resulting voltage also shows that the value is directly proportional to the activity carried out. The highest voltage results of $3.5 \mathrm{~V}$ were obtained after running in place. The voltage value obtained is directly proportional to the activity and frequency of the pulse. The frequency of pulses obtained has a range of 60-97 beats per minute.

\section{CONCLUSION}

The pulse detector is designed using the KY-038 sensor based on Arduino UNO and LabVIEW. The measurements

\section{Acknowledgments}

The author would like to thank LPPM Institut Teknologi Telkom Purwokerto.
[1] R. Syam, "Dasar-Dasar Teknik Sensor", Fakultas Teknik Universitas Hasanuddin, Makasar, 2013.

[2] H. Nurbani, H. Hafidudin, and S. Hadiyoso, "Perancangan dan implementasi alat pendeteksi denyut nadi berbasis mikrokontroler", eProceedings of Applied Science, vol. 1, no. 1, 2014.

[3] N. Muhammad, A. Nur, S. Syahrir, D. Fadlan, and F.H. Musyawira, "Deteksi Denyut Jantung dengan Metode Sensor Pulsh Berbasis Ardiuno", Prosiding Seminar Nasional Teknik Elektro \& Informatika SNTEI 2015, PNUP, Makassar, 11 Juni 2015, hln. 201-206.

[4] B.M. Wibisono, "Rancang Bangun Alat Pendeteksi Detak Jantung Bayi Prematur Menggunakan Pulse Sensor Berbasis Mikrokontroler Yang Terintegrasi Pada Model Inkubator Bayi”, skripsi, Fakultas Teknik, Universitas Lampung, 2018.

[5] M. Olivya, R. Sari, "Perancangan Telehomecare System berba- sis Web Interface Design of Telehomecare System Bassed on Web Interface", Telekontran, vol. 7, no. 2, pp. 185-196, 2019.

[6] Joy-IT, "Datasheet KY-038 Microphone Sound Sensor Module", 2017. Joy-IT - Datasheetspdf.com

[7] Farnell, "Datasheet Arduino Uno', available : https://www. farnell. com /datasheets/1682209.pdf (accessed 20 Januari 2020).

[8] D. Setiawan, "Arduino Uno, It Sharing for Indonesia open knowledge community", ilmuti.org, 2008-2014.

[9] S. Leng, R.S. Tan, K.T.C. Chai, C. Wang, D. Ghista, dan L. Zhong, "The Electronic Stethoscope", Bio Medical Engineering Online, Singapore, 2015.

[10] Wani, Omer Mukhtar, "Signal Processing of Stress Test ECG using MATLAB", International Journal of Engineering Research and Technology (IJERT) vol. 6, no. 8, pp. 175-183, 2017. 